\title{
Role of Intratympanic Steroids in the Management of Idiopathic Sudden Sensori Neural Hearing Loss- Our Experience of 67 Cases
}

\author{
D. S. Deenadayal*, D. Vidyasagar, Vyshanavi Bommakanti, Madisetty Naveen Kumar, \\ Nakirikanti Ravi Kumar, Ramesh Chintha \\ Department of ENT and HNS, Yashoda Hospital, Secunderabad, India \\ Email: *aarticlinic@yahoo.com
}

Received 10 May 2016; accepted 18 July 2016; published 21 July 2016

Copyright (C) 2016 by authors and Scientific Research Publishing Inc.

This work is licensed under the Creative Commons Attribution International License (CC BY).

http://creativecommons.org/licenses/by/4.0/

(c) (i) Open Access

\begin{abstract}
Objective: To assess the outcomes of intratympanic steroids in the management of idiopathic sudden sensorineural hearing loss. Study Design: Retrospective study. Setting: Academic tertiary care medical centre. Materials and Methods: A total of 67 patients with idiopathic sudden sensorineural hearing loss were included in our study. Pre- and post-injection audiograms were taken to assess the outcomes in improvement in hearing. Hearing outcomes were assessed with respect to duration of onset of treatment and age of the patient. Improvement in the speech discrimination score was also assessed. Results: A total of 67 patients were included in our study of which unilateral cases were 59 and bilateral cases were 8 . Subjectively 35 patients reported improvement in hearing after the therapy while objectively we found 44 ears [41 patients] had improvement. The mean PTA pre ITS was 62.7 and after ITS it was 56.3. Maximum improvement was noted at $2000 \mathrm{~Hz}$ and $1000 \mathrm{~Hz}$. Conclusion: Intratympanic steroids can be offered as a first line therapy for idiopathic sudden sensorineural hearing loss as it is minimally invasive, and can be performed as an office based procedure with no systemic side effects. No major complications have been reported in our study and results have been satisfactory.
\end{abstract}

\section{Keywords}

Intratympanic Methyl Prednisolone, Sudden Sensorineural Hearing Loss

\footnotetext{
*Corresponding author, professor and head of the department.
}

How to cite this paper: Deenadayal, D.S., et al. (2016) Role of Intratympanic Steroids in the Management of Idiopathic Sudden Sensori Neural Hearing Loss-Our Experience of 67 Cases. International Journal of Otolaryngology and Head \& Neck Surgery, 5, 174-180. http://dx.doi.org/10.4236/ijohns.2016.54028 


\section{Introduction}

Idiopathic Sudden Sensorineural Hearing Loss [ISSHL] is an otologic emergency that requires quick and prompt management. ISSHL is defined as $30 \mathrm{db}$ or greater hearing loss in three consecutive frequencies occurring within 72 hours or less [1]. The term idiopathic should be applied only after ruling out other causes of sudden hearing loss like noise, trauma, infection, neoplasia, toxic, neurologic and metabolic causes [2].

ISSHL accounts for $1 \%$ of the cases of sensorineural hearing loss [3]. Most of the cases are spontaneous with no attributable risk factor. The pathophysiology is not fully understood with various causes being implicated in the disease causation like viral infection, immunologic diseases, intralabrynthine membrane leaks, vascular occlusion with disturbances in the microcirculation [4].

The first reports of SSHL were reported about 60 years but there are no conclusive guidelines with respect to management of the disease. Silverstein first reported the use of intratympanic steroids in the management of sudden hearing loss [5] and since then intratympanic steroids have gained popularity in the management of various disorders affecting the inner ear.

There are various protocols in the management of ISSHL like antiviral, systemic corticosteroids, anti inflammatory vasodilators and anticoagulants but there is no universally accepted protocol for the management. Many studies have shown efficacy of systemic steroids but the adverse effects of it are well known. Hence to avoid the adverse effects and to have concentration of steroids in the inner ear intratympanic steroids are becoming the latest trend in the management of ISSHL.

In our study we included 67 patients with ISSHL and all of them managed with intratympanic methyl prednisolone as the primary modality of management.

\section{Materials and Methods}

The aim of the study is to assess the outcomes of intratympanic methyl prednisolone injections in management of ISSHL.

This study was conducted in the department of ENT and Head and neck surgery Yashoda Hospital Secunderabad which is a tertiary referral Hospital. The study was conducted with the approval of institute's ethical committee. It was conducted from December 2009 to September 2015.

A total of 67 patients were included in the study and receiving intratympanic steroids. Detailed history was taken from the patients regarding onset of hearing loss, duration of hearing loss, if there was any pre existing ear pathology or any prior viral infection.

Hearing loss was documented with audiometric testing. Tinnitus was graded with tinnitus handicap index inventory by Neumann and McCombe [6] [7]. Pain score following injection was assessed with visual analogue scale [8]. MRI brain with Gadolinium contrast to rule out acoustic neuroma and other retrocochlear lesions.

\subsection{Inclusion Criteria}

1) Sudden onset of hearing loss with less than 72 hours durations with loss of more than $30 \mathrm{db}$ in three consecutive frequencies.

2) Normal MRI Brain with gadolinium contrast.

\subsection{Exclusion Criteria}

1) Patients with age less than 10 years.

2) Patients presenting with vertigo along with hearing loss.

3) History or evidence of acute or chronic otitis media.

4) History of ear surgeries.

5) Patients with history of trauma to the ear.

6) Noise induced hearing loss.

\subsection{Procedure}

The procedure was performed as an Outpatient basis. Patients consent was taken before starting the procedure. The ear was anaesthetised by instilling $4 \%$ lignocaine drops in the ear for ten minutes. With the help of a 0 o 
Karl Storz endoscope a nick was made in the anterosuperior quadrant of tympanic membrane for the air to escape. A mixture of $0.3 \mathrm{ml}$ of injection methyl prednisolone $[125 \mathrm{mg} / \mathrm{ml}]$ and $0.1 \mathrm{ml}$ of $2 \%$ xylocaine was injected into the middle ear through another site in the anterosuperior quadrant of the tympanic membrane [Figure 1]. All patients received four doses of intratympanic steroids with a gap of four days in between the doses. After seven days of completion of the treatment, repeat audiometric testing and grading of tinnitus and vertigo were done. Patients were followed up for a period of 1 year.

\subsection{Definition of Recovery}

Criteria for recovery documented by Haynes DS in their study was used in our study also [9]. Haynes DS used 20-dB improvement in PTA or 20\% improvement in SDS as a criteria for success.

COMPLETE RECOVERY: More than $20 \mathrm{db}$ improvement in 2 consecutive frequencies.

PARTIAL RECOVERY: Improvement between 0 and $20 \mathrm{db}$.

NO RECOVERY: No change in PTA in any of the frequencies.

\section{Results}

A total of 67 patients were included in our study of which unilateral cases were 59 and bilateral were 8 cases. A total of 75 ears received intratympanic steroids. Males were 43 and females were 24 with M:F ratio of 1.7:1. Right ear was affected in 33 and left in 42.

The mean age was 44 years with the youngest patient being 13 years and the oldest patient being 75 years.

\subsection{Improvement in Hearing}

Improvement in hearing was assessed subjectively and objectively. Subjectively 35 patients reported improvement in hearing after the therapy while objectively we found 44 ears [ 41 patients] had improvement. The Mean PTA before ITS was 62.7 while Post PTA was 56.3. Frequency specific improvement is reported in Table 1. Maximum improvement was seen at $2000 \mathrm{~Hz}$ and $1000 \mathrm{~Hz}$.

Out of 44 ears which had improvement-Complete Improvement was seen in 19 ears and Partial improvement was seen in 25 ears. In these 25 ears, there was improvement ranging from 10 to $20 \mathrm{db}$ in 2 consecutive frequencies in 22 ears and 3 ears there was improvement less than $10 \mathrm{db}$. No improvement was seen in 28 ears. In 3 ears there was transient detoriation of hearing which was not more than $10 \mathrm{db}$ from the pre ITS level. The hearing reached the baseline after 1 month of completion of treatment.

\subsection{Correlation of Hearing Improvement with Duration of Onset: [Figure 2]}

We tried to correlate improvement of hearing with respect to duration of onset of treatment. Duration of onset of

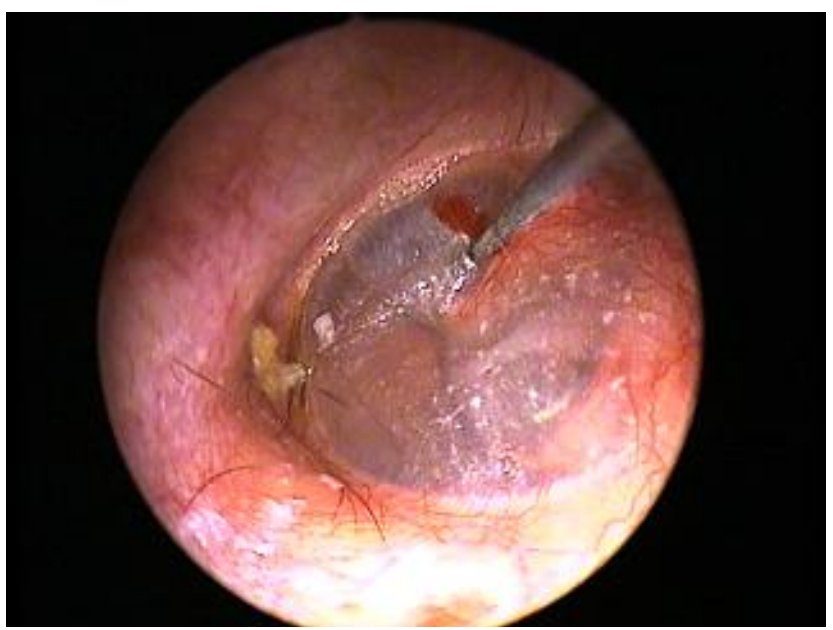

Figure 1. The site of intra tympanic injection in the antero superior quadrant. 
Table 1. Frequency specific improvement in hearing.

\begin{tabular}{cccc}
\hline Frequency & Mean PTA [Pre ITS] & Mean PTA [Post ITS] & Improvement \\
\hline 250 & 46.9 & 41.8 & 5.1 \\
500 & 58.8 & 52.3 & 6.5 \\
1000 & 63.7 & 56.5 & 7.2 \\
2000 & 67.6 & 59.3 & 8.2 \\
4000 & 72.7 & 67.5 & 5.2 \\
8000 & 79.0 & 72.3 & 6.6 \\
\hline
\end{tabular}

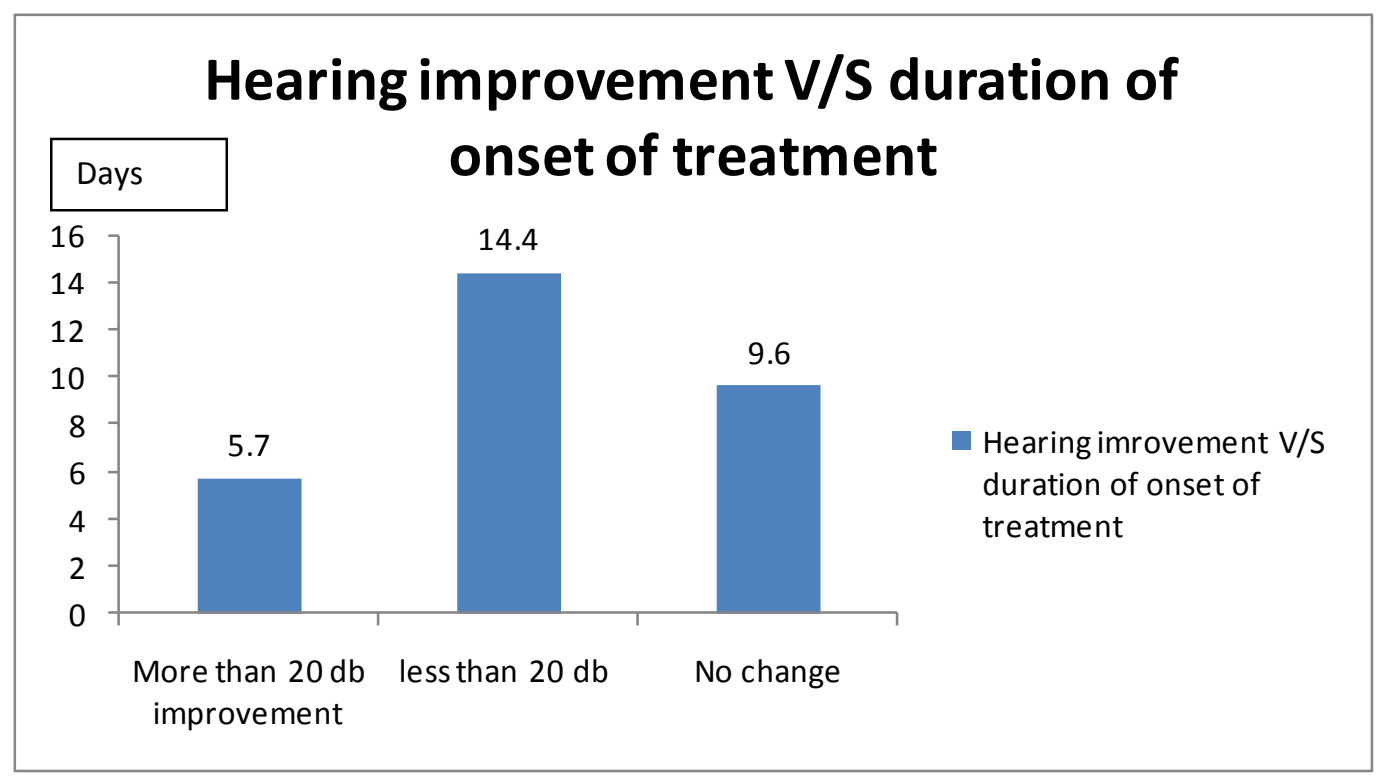

Figure 2. Correlation of hearing improvement with duration of onset.

treatment ranged from 1 day to 38 days with a mean of 10.8 days. We found the patients who had improvement of more than $20 \mathrm{db}$ the mean duration for onset of treatment was 5.7 days. Patients with improvement less than $20 \mathrm{db}$ the mean duration of onset of treatment was 14.4 days and in patients who had no change in hearing the duration was 9.6 days.

\subsection{Correlation with Age: [Figure 3]}

We categorized the patients into 3 groups according to their age and assessed the improvement in hearing. 6 cases [ears] were below the age group of 20 years among them in 4 patients therapy was successful while in 2 patients there was no improvement in hearing. Forty one patients were in the age group of 21 - 50 of which improvement in hearing was seen in 23 cases and no change in 16 cases and worsened in 2 cases. 28 cases were above the age group of 50 years. In these group 16 cases had improvement in hearing while 11 cases there was no change and worsened in 1 case.

\subsection{Improvement in Speech Discrimination Score}

Subjectively 35 patients reported improvement in the clarity of the sounds perceived. Objectively also the Speech discrimination score test was done. Mean Speech discrimination score improved from 49.6 to 55.3.

\subsection{Improvement in Tinnitus}

58 patients complained of tinnitus before therapy and pre THI mean was 0.8 . Post therapy 44 patients reported reduction in tinnitus while in the rest 14 patients it remained the same and post THI was 0.4. 


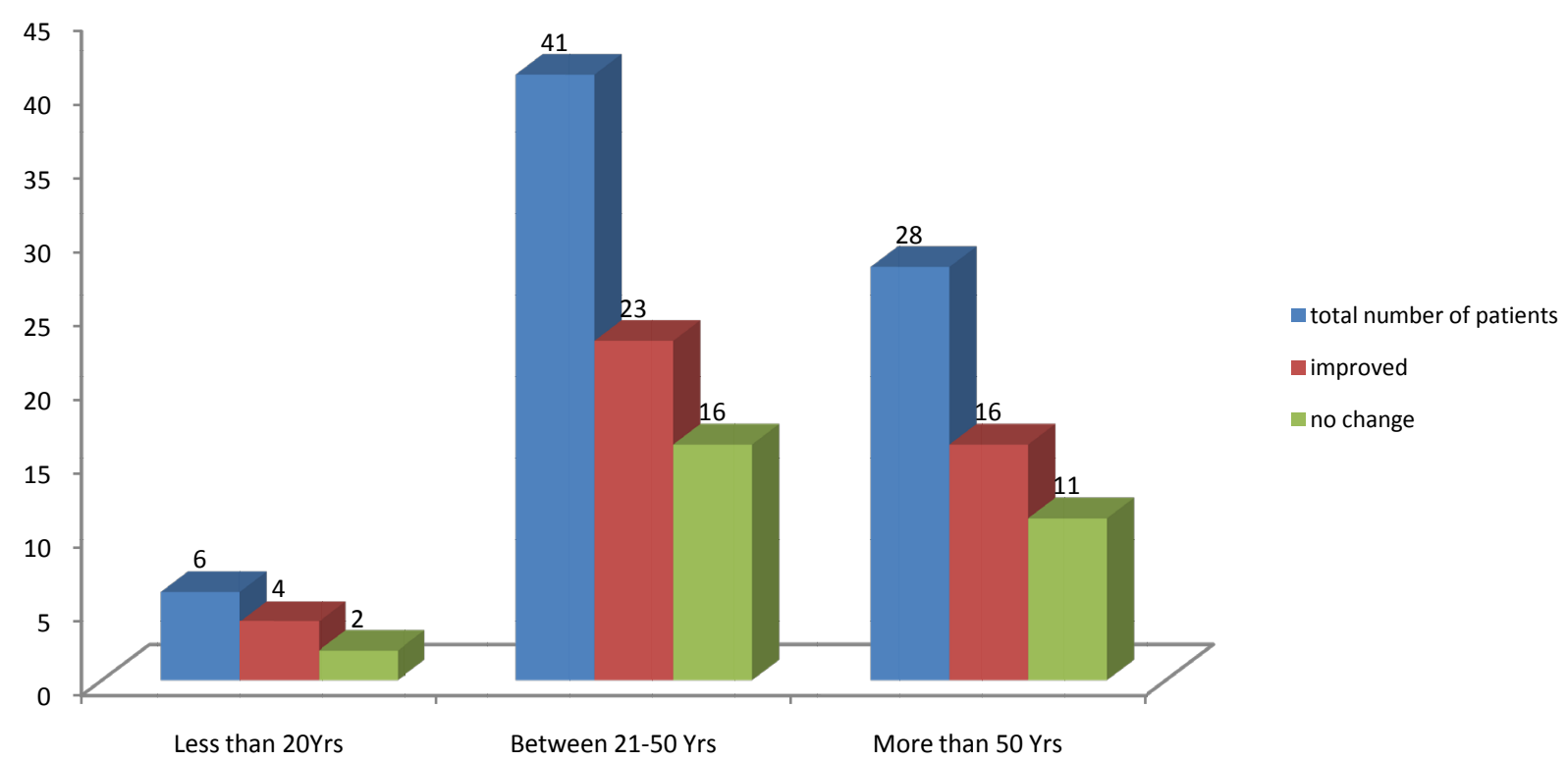

Figure 3. Correlation with age.

\section{Discussion}

Our study included 67 patients and 75 ears. In our study $11.9 \%$ [8 out of 67] of the patients had bilateral pathology while another study by Fetterman reported the incidence of bilateral athology to be 1.7\% in their study [10]. A study by Jeong-Hoon Oh report the incidence of bilateral disease to be very low [11].

In all patients intratympanic methyl prednisolone $0.3 \mathrm{ml}$ with $0.1 \mathrm{ml}$ of $2 \%$ lidocaine was used. A study by Ljiljana Cvorovic et al. report better hearing outcomes with intratympanic methylprednisolone when compared to intratympanic dexamthasone in sudden sensorineural hearing loss [12]. Lidocaine was added to relieve pain. A report by William Slattery support the use of lidocaine to alleviate pain in their Patients [13]. In our patients the Pain score was less than 2.

Subjective improvement in hearing was reported in 52.2\% [35/67] of the patients while objective improvement was found in $61.1 \%$ [41/67] of the patients. 6 patients had objective improvement while they did not have subjective improvement as they fell in profound hearing loss category even after $20 \mathrm{db}$ improvement post therapy. Overall success rate in our study was $61.1 \%$ while in a study done by Khaimook W et al. found overall improvement of $45.2 \%$ [14].

Objective improvement in the PTA by more than $20 \mathrm{~d}$ in 2 consecutive frequencies was the criteria used to COMPLETE RECOVERY in our study. Haynes DS in their study [9] also used the same criteria to define improvement in the hearing outcome.

The mean of the baseline audiogram [PTA average of $500 \mathrm{~Hz}$ to $4 \mathrm{~Hz}$ ] before and after 1 year of treatment was 62.7 and 56.3 respectively. A study done in china by Li Peng reported improvement from $64.8 \mathrm{db}$ to $52.9 \mathrm{db}$ [15].

A maximum improvement was seen at $2000 \mathrm{~Hz}$ and $4000 \mathrm{~Hz}$. Improvements in mid frequency was higher compared to low frequeny and high frequency. While we found improvement at 2000 an 5000 hz, Yang et al. reported improvement at $250 \mathrm{~Hz}$ [16].

We tried to correlate the maximum gain in hearing with the duration of onset of treatment. The mean duration was 5.7 days in patients who had more than $20 \mathrm{db}$ improvement. A study done by Haynes DS reported no benefit of intratympanic steroid injections in patients beyond 36 days of onset of SSNHL but this did not correlate with our study [9].

In the patients below the age of 20 years - 66.6\% [4/6] of the patients showed improvement while $56.0 \%$ [23/41] of the patients between the age group of 21 - 50 had improvement and 57.1\% [16/28] above the age of 50 had improvement. Younger age responded better compared to the older age group. Wilson et al. reported age as a prognostic factor to determine the improvement of hearing. Patients with age less than 40 years respond better compared to older patients [1]. 
Detoriation of hearing was not reported subjectively by any of the patients but objectively 3 patients had transient worsening of hearing which was not more than $10 \mathrm{db}$ and this recovered within 1 month of completion of treatment. Chen Y et al. reported a study in 36 patients who received intratympanic injections. Among the 36 patients only 1 patient had worsening of hearing [17].

35 patients [60.3\%] reported subjective improvement in the clarity of sounds. Mean SDS improved from 49.6 to 55.3 .

Subjective reduction in tinnitus was seen in 75.8\% [44/58].

None of the patients reported any major complications. Only transient nausea, vertigo and pain were reported by the patients. A report by Li Peng also describes no major complications in their study and only one patient developed persistent tympanic membrane perforation [15].

Sudden sensorineural hearing loss is a true otological emergency which requires to be managed effectively. Thorough evaluation of the patient is mandatory before starting any type of therapy. Various Studies indicate different modalities of treatment for this condition but in our centre we chose intratymapnic methylprednisolone as the first line of therapy in all patients with sudden sensorineural hearing loss.

\section{Conclusion}

Intratympanic steroids can be offered as a first line therapy for sudden sensorineural hearing loss as it is minimally invasive and can be performed as an office based procedure with no systemic side effects. No major complications have been reported in our study and results have been satisfactory.

\section{References}

[1] Wilson, W.R., Byl, F.M. and Laird, N. (1980) The Efficacy of Steroids in the Treatment of Idiopathic Sudden Hearing Loss. A Double-Blind Clinical Study. Archives of Otolaryngology, 106, 772-776.

http://www.ncbi.nlm.nih.gov/pubmed/7002129 http://dx.doi.org/10.1001/archotol.1980.00790360050013

[2] Goravalingappa, R. and Bhattacharyya, A.K. (1997) Sudden Sensorineural Hearing Loss: An Update. Indian Journal of Otolaryngology and Head \& Neck Surgery, 49, 87-91.

[3] Hughes, G.B., Freedman, M.A., Haberkamp, T.J. and Guay, M.E. (1996) Sudden Sensorineural Hearing Loss. Otolaryngologic Clinics of North America, 29, 393-405. http://www.ncbi.nlm.nih.gov/pubmed/8743339

[4] Anderson, R.G. and Meyerhoff, W.L. (1983) Sudden Sensorineural Hearing Loss. Otolaryngologic Clinics of North America, 16, 189-195. http://www.ncbi.nlm.nih.gov/pubmed/6856305

[5] Raymundo, I.T., Bahmad, F., Barros Filho, J., Pinheiro, T.G., Maia, N.A. and Oliveira, C.A. (2015) Intratympanic Methylprednisolone as Rescue Therapy in Sudden Sensorineural Hearing Loss. Brazilian Journal of Otorhinolaryngology, 76, 499-509. http://www.ncbi.nlm.nih.gov/pubmed/20835538 http://dx.doi.org/10.1590/S1808-86942010000400015

[6] Newman, C.W., Jacobson, G.P. and Spitzer, J.B. (1996) Development of the Tinnitus Handicap Inventory. Archives of Otolaryngology—Head and Neck Surgery, 122, 143-148. http://www.ncbi.nlm.nih.gov/pubmed/8630207 http://dx.doi.org/10.1001/archotol.1996.01890140029007

[7] McCombe, A., Baguley, D., Coles, R., McKenna, L., McKinney, C. and Windle-Taylor, P. (2001) Guidelines for the Grading of Tinnitus Severity: The Results of a Working Group Commissioned by the British Association of Otolaryngologists, Head and Neck Surgeons, 1999. Clinical Otolaryngology and Allied Sciences, 26, 388-393.

http://www.ncbi.nlm.nih.gov/pubmed/11678946 http://dx.doi.org/10.1046/j.1365-2273.2001.00490.x

[8] Breivik, H., Borchgrevink, P.C., Allen, S.M., et al. (2008) Assessment of Pain. British Journal of Anaesthesia, 101, 17-24. http://dx.doi.org/10.1093/bja/aen103

[9] Haynes, D.S., O’Malley, M., Cohen, S., Watford, K. and Labadie, R.F. (2007) Intratympanic Dexamethasone for Sudden Sensorineural Hearing Loss after Failure of Systemic Therapy. Laryngoscope, 117, 3-15. http://dx.doi.org/10.1097/01.mlg.0000245058.11866.15

[10] Fetterman, B.L., Luxford, W.M. and Saunders, J.E. (1996) Sudden Bilateral Sensorineural Hearing Loss. Laryngoscope, 106, 1347-1350. http://dx.doi.org/10.1097/00005537-199611000-00008

[11] Oh, J.-H., Park, K., Lee, S.J., Shin, Y.R. and Choung, Y.-H. (2007) Bilateral versus Unilateral Sudden Sensorineural Hearing Loss. Otolaryngology—Head and Neck Surgery, 136, 87-91. http://dx.doi.org/10.1016/j.otohns.2006.05.015

[12] (2016) Intratympanic Steroid Treatment in Idiopathic Sudden Sensorineural Hearing Loss. A Control Study. 
http://connection.ebscohost.com/c/articles/44523848/intratympanic-steroid-treatment-as-primary-therapy-idiopathic-su dden-sensorineural-hearing-loss

[13] Slattery, W.H., Fisher, L.M., Iqbal, Z., Friedman, R.A. and Liu, N. (2005) Intratympanic Steroid Injection for Treatment of Idiopathic Sudden Hearing Loss. Otolaryngology—Head and Neck Surgery, 133, 251-259. http://dx.doi.org/10.1016/j.otohns.2005.05.015

[14] Khaimook, W. and Jantarapattana, K. (2011) Therapy of Idiopathic Sudden Sensorineural Hearing Loss with Intratympanic Steroid Injection. Journal of the Medical Association of Thailand, 94, 1495-1499. http://www.ncbi.nlm.nih.gov/pubmed/22295738

[15] Li, P., Zeng, X.-L., Ye, J., Yang, Q.-T., Zhang, G.-H. and Li, Y. (2011) Intratympanic Methylprednisolone Improves Hearing Function in Refractory Sudden Sensorineural Hearing Loss: A Control Study. Audiology and Neurotology, 16, 198-202. http://dx.doi.org/10.1159/000320838

[16] Yang, H.C., Cho, Y.B., Jang, C.H. and Cho, H.-H. (2015) Efficacy of Concomitant Intratympanic Steroid Injection for Sudden Deafness According to Initial Hearing Loss. Otology \& Neurotology, 36, 1604-1609. http://dx.doi.org/10.1097/MAO.0000000000000869

[17] Chen, Y., Wen, L., Hu, P., Qiu, J., Lu, L. and Qiao, L. (2010) Endoscopic Intratympanic Methylprednisolone Injection for Treatment of Refractory Sudden Sensorineural Hearing Loss and One Case in Pregnancy. Journal of Otolaryngology—Head \& Neck Surgery, 39, 640-645. http://www.ncbi.nlm.nih.gov/pubmed/21144358

\section{Submit or recommend next manuscript to SCIRP and we will provide best service for you:}

Accepting pre-submission inquiries through Email, Facebook, Linkedin, Twitter, etc A wide selection of journals (inclusive of 9 subjects, more than 200 journals)

Providing a 24-hour high-quality service User-friendly online submission system

Fair and swift peer-review system

Efficient typesetting and proofreading procedure

Display of the result of downloads and visits, as well as the number of cited articles

Maximum dissemination of your research work

Submit your manuscript at: http://papersubmission.scirp.org/ 